\title{
Las confesiones de un médico, de Silverio Domínguez [1882]: medicina popular, curanderismo y médicos extranjeros en Buenos Aires a fines del siglo XIX
}

Resumen: El objetivo de este artículo es repensar, con base en la recuperación y el análisis de las producciones escritas más tempranas del médico español Silverio Domínguez, las características esenciales de tres tópicos que fueron muy significativos de la historia de la medicina y de la salud en el territorio bonaerense durante el último tercio del siglo XIX: la situación de los profesionales extranjeros, el curanderismo y la medicina popular. Tanto en su novela autobiográfica de 1882, Las confesiones de un médico, como en otros textos menores, Domínguez, quien se había instalado en 1874 en Argentina, brindó un testimonio valioso, pero poco conocido, acerca de esas problemáticas.

Palabras clave: curanderismo, medicina popular, moral médica, médicos extranjeros.

\section{Las confesiones de un médico by Silverio Domínguez [1882]: popular medicine, quackery and foreign doctors in Buenos Aires at the end of the 19th century}

Abstract: Based on the reassessment and analysis of Silverio Dominguez's earliest writings, this paper aims to rethink the essential characteristics of three topics that were very significant in the history of medicine in Buenos Aires during the last third of the 19th century: the situation of foreign doctors, quackery, and popular medicine. In his autobiographical novel of 1882, Las confesiones de un médico [A Physician's Confessions], as in other minor texts, this Spanish physician who had settled in Argentina in 1874 provided valuable but little-known testimonies about these problems.

Keywords: quackery, popular medicine, medical morality, foreign physicians.

\section{Las confesiones de un médico, de Silverio Domínguez [1882]: medicina popular, curandeirismo e médicos estrangeiros em Buenos Aires no final do século XIX}

Resumo: 0 objetivo deste artigo é repensar, a partir da recuperação e da análise das primeiras produções escritas do médico espanhol Silveiro Domínguez, as características essenciais de três tópicos que foram muito significativos na história da medicina e da saúde no território bonaerense durante o último terço do século XIX: a situação dos profissionais estrangeiros, o curandeirismo e a medicina popular. Tanto no seu romance autobiográfico de 1882, Las confesiones de un médico, como em outros textos menores, Domínguez, que se havia instalado em 1874 na Argentina, proporcionou um testemunho precioso, mas pouco conhecido, sobre essas problemáticas.

Palavras-chave: curandeirismo, medicina popular, moral médica, médicos estrangeiros.

Cómo citar este artículo: Mauro Vallejo y Astrid Dahhur, "Las confesiones de un médico, de Silverio Domínguez [1882]: medicina popular, curanderismo y médicos extranjeros en Buenos Aires a fines del siglo XIX”, Trashumante. Revista Americana de Historia Social 18 [2021]: 76-98.

DOI: 10.17533/udea.trahs.n18a04

Fecha de recepción: 9 de junio de 2020

Fecha de aprobación: 2 diciembre de 2020

Mauro Vallejo: Doctor en Psicología por la Universidad Nacional de La Plata, Argentina. Investigador adjunto del Consejo Nacional de Investigaciones Científicas y Técnicas [Conicet]. ORCID: 0000-0002-1712-2181.

Correo electrónico: maurosvallejo@gmail.com

*A

Astrid Dahhur: Doctora en Historia por la Universidad Católica Argentina. Becaria posdoctoral del Consejo Nacional de Investigaciones Científicas y Técnicas [Conicet]. ORCID: 0000-0001-6535-0819.

Correo electrónico: astriddahhur@uca.edu.ar 


\title{
Las confesiones de un médico, de Silverio Domínguez [1882]: medicina popular, curanderismo y médicos extranjeros en Buenos Aires a fines del siglo XIX
}

\author{
Mauro Vallejo y Astrid Dahhur \\ Introducción
}

$\mathrm{E}_{\mathrm{a}}^{\mathrm{n}}$ el prefacio a un libro publicado en Buenos Aires en 1894, el autor ironizaba éxito de público: “i¡Otra vez sale este señor con un libro más!!... De seguro que no tiene bien ajustados los tornillos [...] Porque mis libros como no se venden, nadie los lee por consecuencia, y ahí están arrinconados en las librerías sin que alma caritativa alguna trate de sacarlos de ese purgatorio". ${ }^{1}$ Quien redactó esas líneas era, en efecto, un autor prolífico que durante su larga vida dio a la imprenta volúmenes y escritos de diversa naturaleza: artículos científicos, ficciones literarias, crónicas costumbristas, obras de divulgación, relatos de viaje, entre otros. Nos referimos al médico español Silverio Domínguez Sáenz. Nacido en Soto en Cameros (La Rioja, España) en junio de 1852, este diplomado desarrolló una parte importante de su carrera profesional en territorio argentino, primero en pueblos del interior de la provincia de Buenos Aires, y luego en la ciudad capital del país.

Tras obtener su diploma médico en la Universidad de Valladolid, Domínguez emigró en 1874 hacia la República Argentina, y revalidó su diploma cuatro años más tarde. ${ }^{2}$ Luego de ejercer durante ocho años en pequeños pueblos, sobre todo en Arrecifes (ubicado en el norte de la provincia, a 170 kilómetros de la ciudad

* Este artículo fue realizado con el apoyo de la beca interna postdoctoral en Temas Estratégicos del Conicet (2020-2022). PICTO UCA 2017-0064 IF2018-55785184-APN-FONCYT-ANPCH: "Comprender la religión más allá de las 'religiones': El rol de los grupos lábiles y la cultura de masas en la circulación de significados y prácticas religiosas heterodoxas durante el siglo XX", dirigido por el Dr. Alejandro Frigerio en el Instituto de Investigaciones, Facultad de Ciencias Sociales de la Universidad Católica Argentina (IICS-UCA).

1. Silverio Domínguez, La tuberculosis o confidencias microbianas (Buenos Aires: Imprenta Roma, 1894) 5.

2. Florencio Fernández Gómez, Guía médica de Buenos Aires (Buenos Aires: Imprenta Europea, 1893) 305. 
de Buenos Aires), hacia 1882 se instaló en este gran centro urbano, donde casi de inmediato tuvo una labor destacada en el terreno de la bacteriología. Al respecto, ha de ser subrayado el carácter algo sorprendente de su itinerario profesional: el médico que hacia comienzos de la década de 1880 obtuvo cierta notoriedad merced al elogio de los remedios populares empleados en los pueblos de la provincia, a mediados de esa misma década se destacaba como uno de los principales especialistas locales de la ciencia de Pasteur y Koch.

Sin embargo, este artículo no pretende trazar su biografia de manera exhaustiva. ${ }^{3}$ El objetivo, por el contrario, es utilizar algunas de las primeras obras que publicó, especialmente su novela de 1882, Las confesiones de un médico, así como otros escritos menores que establecen con esa ficción un diálogo productivo, con el objetivo de repensar tres tópicos que resultaron esenciales en el desenvolvimiento de la medicina bonaerense del último tercio del siglo XIX, y que aún aguardan un análisis histórico documentado. Nos referimos a la situación de los médicos extranjeros, el curanderismo y la medicina popular. ${ }^{4}$

Al tiempo que escasean las monografias o estudios acerca de las tareas efectuadas por Domínguez en Argentina, ninguno de esos trabajos ha tomado en consideración las fuentes que aquí retienen nuestra atención y, en consecuencia, no han ponderado su poder testimonial en lo relativo a esos tres asuntos. ${ }^{5}$ Para llevar adelante el cometido, se propone, por un lado, cotejar el contenido del libro de

3. Si bien somos conscientes de que empleamos un documento autobiográfico, con todas las limitaciones y ventajas que ello conlleva, decidimos no realizar una biografia de Silverio Domínguez, sino emplear su testimonio como un medio para reconstruir diferentes cuestiones ligadas a la situación sanitaria de la provincia de Buenos Aires. Igualmente, consideramos que: "La memoria autobiográfica se construye sobre las experiencias vividas individualmente; el sujeto es el actor y protagonista del relato". Alexia Sanz Hernández, "El método biográfico en investigación social: potencialidades y limitaciones de las fuentes orales y los documentos personales", Asclepio 57.1 (2005): 106, doi: 10.3989/asclepio.2005.v57.i1.32. En este sentido, aunque no realicemos una biografia, sabemos que sus palabras están mediadas por sus emociones, vivencias, resignificaciones y que su testimonio es una reconstrucción de los hechos acontecidos bajo la lente de una persona en particular. En consecuencia, contrastarlo con otros documentos es imprescindible.

4. Silverio Domínguez, Las confesiones de un médico (Buenos Aires: El Correo Español, 1882).

5. El libro de María Silvia Di Liscia contiene seguramente el análisis más cuidadoso de algunas de las publicaciones de Domínguez durante su periodo bonaerense, puntualmente acerca de su ponderación de los remedios populares contra el empacho. María Silvia Di Liscia, Saberes, terapias y prácticas médicas en Argentina (1750-1910) (Madrid: Consejo Superior de Investigaciones Científicas, 2002) 195-196. Una tesis de licenciatura reciente ha recuperado los trabajos de Domínguez en el área de la bacteriología posteriores a 1886. Nicolás Rojas, "Conocimientos bacteriológicos, trayectorias institucionales e intervención sanitaria: la creación del Instituto Bacteriológico del Departamento Nacional de Higiene (1886-1904)" (Tesis de licenciatura en Historia, Universidad Nacional de Quilmes, 2019). Algunos datos generales sobre este médico figuran en Alfredo Kohn Loncarica, "Historia de la inmigración médica en la República Argentina" (Tesis de doctorado en Medicina, Universidad de Buenos Aires, 1981). Para entender la escasa atención que la historiografia ha prestado a Las confesiones de un médico, es menester considerar que, por razones que no resultan evidentes, no figura en las bibliotecas o repositorios documentales más importantes de Buenos Aires. 
1882 con otras producciones contemporáneas del autor, a fin de demostrar que el primero contiene la narración autobiográfica del médico, quien en ese momento hacía la transición del interior a la capital. Por ese motivo, todas esas fuentes merecen ser tomadas no tanto como los reveladores de los puntos de vista o las experiencias personales del principal implicado, sino más bien como registros o rastros elocuentes que tienen el poder de patentizar dinámicas y procesos históricos que afectaron tanto a ese protagonista como a otros agentes sociales. Entre las dinámicas, mediaciones y conflictos que tienen allí una franca visibilidad, figuran aquellos que, o bien constituyen zonas aún escasamente indagadas por los especialistas (verbigracia, la situación de los médicos extranjeros), o sobresalen como puntos renovadores de recientes líneas de investigación que están permitiendo aprehender con mejor luz la medicina argentina de la segunda mitad del siglo XIX. Aquí cabe anotar la convivencia obligada entre sanadores diplomados y no diplomados, así como la mutua interdependencia de los saberes de unos y otros, ante todo en ciudades pequeñas o zonas rurales. ${ }^{6}$ Por otro lado, se mostrará la resonancia entre numerosos elementos de la obra de 1882 y otras fuentes.

El presente artículo está dividido en tres secciones. En la primera, se realizan algunas precisiones acerca del libro de 1882, y se señalan algunos rasgos de su trama. Al mismo tiempo, se reconstruirán de modo sucinto las intervenciones previas e inmediatamente posteriores de Domínguez, sobre todo en las páginas de la Revista Médico-Quirúrgica, merced a las cuales el autor logró desde temprano hacerse un nombre en el panorama profesional del Río de la Plata. La segunda sección se enfoca en las consideraciones que Domínguez efectuó en Las confesiones de un médico acerca del ejercicio de la medicina en pequeños pueblos; el cotejo de esos fragmentos con otras fuentes relativas a ese mismo tópico resulta provechoso para construir un relato más acabado a propósito, por ejemplo, de las relaciones siempre tensas mantenidas entre médicos y autoridades judiciales o políticas, o de la necesidad de pensar el nexo entre médicos y curanderos con

6. Al trabajo ya clásico de Di Liscia, se han sumado de modo reciente más indagaciones acerca de otras zonas contextuales, que muchas veces aprovechan materiales de archivos judiciales y administrativos. Véanse los trabajos de Irina Podgorny, Charlatanería y cultura científica en el siglo XIX (Madrid: Libros de la Catarata, 2015); José Ignacio Allevi, Adrián Carbonetti y Paula Sedrán, "Médicos, administradores y curanderos. Tensiones y conflictos al interior del arte de curar diplomado en la Provincia de Santa Fe, Argentina (1861-1902)", Anuario de Estudios Americanos 75.1 (2018): 295-322, doi: 10.3989/aeamer.2018.1.11; José Ignacio Allevi y Adrián Carbonetti, "Peticiones y prerrogativas. Médicos y boticarios en la corporativización del arte de curar y la conformación del Estado provincial en Santa Fe, Argentina (1857-1903)", Varia Historia 35.69 (2019): 753-786, doi: 10.1590/0104-87752019000300004; Mirta Fleitas, "iQueremos a Mano Santa!: actores y significados de una revuelta popular acontecida en 1929 en San Salvador de Jujuy", Salud Colectiva 3.3 (2007): 301-313, doi: 10.18294/sc.2007.149; Astrid Dahhur, "Las causas del curanderismo según la prensa en Tandil y en Buenos Aires a principios del siglo XX", Question 1.59 (2018): 1-19, doi: 10.24215/16696581e063; Astrid Dahhur, "La medicina popular a través de las fuentes judiciales. El proceso de medicalización en la provincia de Buenos Aires a fines del siglo XIX y mediados del siglo XX”, e-l@tina. Revista Electrónica de Estudios Latinoamericanos 17.66 (2019): 48-67. 
grillas interpretativas que rebasen el esquema del rechazo o la represión. La tercera sección se ocupa de recortar los enunciados del volumen de 1882 relativos a las condiciones en que los médicos foráneos desempeñaban sus labores tanto en la "campaña” como en la capital. A través de la puesta en diálogo de esos fragmentos con otras fuentes primarias y secundarias afines, este artículo aspira a mostrar la potencialidad ilustrativa de Las confesiones en lo atinente a un asunto sobre el cual aún se sabe bastante poco.

\section{Una novela olvidada}

El libro Las confesiones de un médico fue publicado a fines de 1882 por la imprenta de El Correo Español, el diario más importante de la comunidad española residente en Buenos Aires. El autor no resultaba un desconocido para el público de la urbe, pues ya había editado al menos dos libros destinados a lectores no especializados, así como trabajos científicos en las revistas médicas de la ciudad. En efecto, en 1880 había dado a la imprenta, de forma anónima, un breve volumen autobiográfico titulado Recuerdos de la niñez. Un año más tarde, nuevamente sin firma, había editado un pequeño folleto en el que denunciaba los perjuicios morales provocados por la afición al juego. ${ }^{7}$ En lo que respecta a las revistas profesionales, antes de 1882 el médico español había dado a la luz tres intervenciones. Por un lado, en su calidad de miembro corresponsal del Círculo Médico Argentino, envió a esa agrupación un conciso folleto acerca del tratamiento de la difteria. De forma anticipada al mensaje que habría de remarcar en comunicaciones ulteriores, sostenía en esas páginas que, tras comprobar la ineficacia de los remedios defendidos en los manuales científicos, había podido observar el poder bienhechor de un método ideado por un médico del pueblo de Pergamino "tan instruido como humilde". 8 Unos meses más tarde, en mayo de 1881, la Revista Médico-Quirúrgica publicó una carta de aquel profesional, en la cual criticaba algunos excesos cometidos por los curanderos del interior. A decir verdad, la esquela combinaba dos elementos: en principio, Domínguez decía aceptar la existencia del curanderismo, siempre y cuando esa "intrusión" fuera ejercida dentro de ciertos límites y con buena fe, mas luego condenaba en duros términos el accionar de un "desgraciado monomaníaco" que por esos días ejercía su arte en Arrecifes. ${ }^{9}$ No resulta claro si la nota se refería directamente a Pancho Sierra, el célebre curandero de Pergamino, o a un émulo o discípulo de aquel, ${ }^{10}$ pero finalizaba con un llamado a "desterrar el curanderismo con todo el rigor de la ley".

7. Silverio Domínguez, Perfiles de una llaga social (Buenos Aires: Imprenta de Pablo Coni, 1881).

8. Silverio Domínguez, Tratamiento de la difteria (Buenos Aires: Imprenta de Pablo Coni, 1880) 4.

9. “Carta del Dr. Domínguez", Revista Médico-Quirúrgica (Buenos Aires) 8 de mayo de 1881:50-51.

10. Podría tratarse, en efecto, de Pancho Sierra, pues consta que ese sanador también trabajó en Arrecifes, Rojas y Salto. Eva Romero de Torres, El Gaucho de Dios. Vida y obra de Pancho Sierra (Merlo: El Triángulo, 1982) 41. Sea como fuere, es evidente que Domínguez conocía el prestigio que había adquirido Sierra.Véase Domínguez, Las confesiones 119-123. 
Apenas unos meses más tarde, el 23 de septiembre de 1881, la misma revista inició la publicación, en once entregas, de un extenso trabajo de Domínguez titulado "Apuntes de un médico de campaña". ${ }^{11}$ Se revisarán esas páginas en el apartado siguiente, pues conforman un valioso texto paralelo de la novela de 1882; se puede adelantar que dichas entregas contienen un rico acopio de remedios populares usados por esos años en los pueblos de la provincia, así como una esclarecedora descripción de las dificultades que los diplomados debían atravesar al ejercer su arte en aquellas latitudes.

Al publicar su obra Las confesiones de un médico, Domínguez apela a la siguiente táctica: a través de la introducción, presenta a la novela como el manuscrito que le había confiado, instantes antes de morir, un médico llamado Felipe. El recurso tiene aquí una particularidad: todo se sostiene en la ficción según la cual Domínguez ha recibido el texto inédito mientras ejerce su arte médico en algún poblado de España.Tanto en el prólogo como en diversos tramos de su presunta autobiografía, Felipe intenta convencer a sus lectores sobre la poca conveniencia que reviste que los jóvenes de origen humilde opten por la formación universitaria en profesiones liberales. Los ocho capítulos de la novela son una cansina demostración de ese mensaje. En efecto, cada capítulo relata un recorte particular de la trágica y esforzada biografia de Felipe: su nacimiento en un "pueblo de cuatrocientos vecinos de Castilla la Vieja", ${ }^{12}$ los planes de sus padres para convertirlo en sacerdote, sus primeros y fallidos estudios en un seminario, su posterior elección de la carrera de medicina; una vez recibido, prueba suerte en su región, pero allí le resulta imposible ganarse el pan, por lo cual resuelve trasladarse a América. Los capítulos cuarto, quinto y sexto (que en términos de extensión ocupan la mitad de la novela) relatan los años en que Felipe trabajó como médico, siempre en pueblos de la provincia de Buenos Aires. Tras múltiples contratiempos y reveses económicos, emprendió el regreso a su pueblo español, y los dos últimos capítulos de la novela están dedicados a su triste y corta permanencia en su patria, donde muere alejado de sus hijos. La obra se cierra con un epílogo, en el cual retorna la voz narrativa de Domínguez, esta vez para hacer suyas las conclusiones que se desprendían de la biografia de Felipe.

Cabe mencionar que se encontró solamente una reseña de la obra de Domínguez, publicada en el Anuario Bibliográfico, y escrita por Alberto Navarro Viola. A pesar de que este acusó de rústica y poco original a la tesis transmitida de modo redundante por la novela, destacó la naturaleza fidedigna de las imágenes locales utilizadas. ${ }^{13}$ Es precisamente esa virtud de la novela la que vertebra el examen que se emprenderá en las páginas que siguen. Los recuerdos plasmados por Domínguez (torpemente camuflado detrás del heterónimo Felipe) sobre su vida en

11. La última contribución se imprimió en la Revista Médico-Quirúrgica el 23 de febrero de 1882.

12. Domínguez, Las confesiones 11.

13. "Pero el libro vale por sus detalles. Es minucioso, traslada con felicidad escenas de provincia, escenas de la vida real que aparecen con todo su colorido [...], retratos, en fin, de personas que uno cree reconocer". Anuario Bibliográfico de la República Argentina IV (Buenos Aires) 1883: 302. 
Argentina desde 1874, conforman un reservorio testimonial sobre procesos que, amén de ser esenciales para el desenvolvimiento de la medicina vernácula, generan aún muchas incógnitas debido a la escasa documentación que existe para poder echar luz sobre ellos.

\section{Campaña, curanderismo y moral médica}

Las páginas en que Domínguez recupera las primeras vivencias en la ciudad de Buenos Aires son, sin lugar a dudas, un testimonio vívido de una realidad que con el correr de los años compartirían muchos otros médicos extranjeros. Allí relata sus muchas sorpresas, tanto por la buena formación científica de los estudiantes locales, como por las exigencias que se imponían a los diplomados foráneos. "Suponía escasez de médicos en Buenos Aires, y veo que tiene trescientos, y muchos de ellos de notoria competencia y celebridad". ${ }^{14}$ La cifra parece bastante ajustada a la realidad; según el censo de 1869 había en la capital 154 médicos, pero ese número se incrementaba año a año, en gran medida gracias al caudal de diplomados traídos por la inmigración. Así, para 1895, el número de doctores había crecido hasta 646. Para el caso de la provincia, entre esos años se pasó de 89 a 321 médicos en total. ${ }^{15}$

Enterado del modo en que debía proceder para revalidar su diploma — punto que trataremos con más detalle en el próximo apartado-, el protagonista decide mudarse a "un pequeño pueblo de campo" a fin de reunir el dinero suficiente para costearse el examen, y con el objetivo adicional de mejorar sus insuficientes conocimientos científicos. ${ }^{16}$ Se trata, a todas luces, de un testimonio más que fiel de lo realizado por el autor en la vida real: se sabe con certeza que el médico español hizo ese recorrido apenas desembarcado en el país, pues entre 1874 y 1882, residió en Arrecifes (y probablemente también en otros poblados cercanos).

Según los términos utilizados en la ficción, se trasladó a un pueblo de la provincia, "donde se me había dicho que no había médico, y que podría ejercer mi profesión sin que nadie me molestara". ${ }^{17} \mathrm{Al}$ proceder de ese modo, el médico extranjero se amoldaba a una práctica habitual y legítima. En efecto, la Ley del Ejercicio de la Medicina sancionada por la legislatura de Buenos Aires el 18 de julio de 1877 establecía, en su artículo segundo, que los médicos extranjeros que no hubieran realizado la reválida podían ejercer la profesión, por un tiempo limitado, "en aquellos parajes donde no hubiere médicos recibidos". ${ }^{18}$ De esa manera, se intentaba incentivar el flujo de diplomados a poblaciones en las que el cuidado de la salud quedaba generalmente en manos

14. Domínguez, Las confesiones 97.

15. María Laura Rodríguez y otros, “Ocupaciones de la salud en el territorio argentino: perspectivas a partir de los censos nacionales de 1869, 1895 y 1914”, Política \& Sociedad 25.1 (2018): 75-101.

16. Domínguez, Las confesiones 103.

17. Domínguez, Las confesiones 103.

18. Emilio R. Coni, Código Médico Argentino. Recopilación y resumen de la legislación y jurisprudencia sobre la profesión, deberes y derechos de los médicos, farmacéuticos y parteras (Buenos Aires: Imprenta de Pablo E. Coni, 1879) 111. 
de empíricos o boticarios. ${ }^{19}$ Si bien en comparación con otras provincias del país, la de Buenos Aires poseía el índice más alto de médicos por cantidad de habitantes (en 1869, había 0.49 médicos por cada mil habitantes, siendo la media del país de apenas 0.26), lo cierto es que en todo el territorio provincial había para 1869 solo 89 facultativos, y la distribución de esos profesionales era muy desigual, pues solían concentrarse en los grandes centros urbanos. ${ }^{20}$

A partir de allí la novela contiene información sumamente valiosa acerca del desempeño de la medicina en un contexto semi rural, y es a propósito de todo ello que las páginas de las memorias establecen un diálogo fecundo con el escrito "Apuntes de un médico de campaña" y con otras contribuciones del autor.

Los médicos locales hicieron saber rápidamente su preocupación acerca de la extensión del curanderismo en la provincia; expresaron asimismo su repulsa contra la laxitud de los controles emprendidos por las débiles agencias estatales que debían vigilar el ejercicio de la medicina, ${ }^{21} \mathrm{y}$, por último, intentaron atribuir el éxito de los no diplomados a la ignorancia de los habituales consumidores de sus servicios. Con el correr de los años, y a medida que la medicina tenía cierto éxito en algunos de sus propósitos y reivindicaciones, tales como fortalecer sus agrupamientos profesionales, "modernizar" los planes de enseñanza de su ciencia o ser incluida en el trabajo de agencias estatales ligadas a la higiene, la queja respecto de la existencia del curanderismo, tanto en la provincia como en la ciudad capital, apeló siempre a ese argumento relativo a la ignorancia. ${ }^{22}$ Según esas argumentaciones, el desconocimiento debía ser atribuido a los curanderos (que mientras menos sabían sobre la verdadera naturaleza de las enfermedades, más se esmeraban en perfeccionar sus tácticas de engaño y taumaturgia), pero sobre todo a los clientes. En ese sentido, los escritos de Silverio Domínguez aportan una comprensión alternativa que adquiere una valiosa significación para la mirada historiadora.

A simple vista, el médico español no haría más que repetir los enunciados de sus colegas. En efecto, en sus páginas abundan las diatribas contra el accionar de los curanderos en la provincia, y al mismo tiempo recrimina a las autoridades judiciales la endeblez de sus medidas represivas. En el apartado anterior se hizo alusión

19. Ricardo González Leandri, Curar, persuadir, gobernar. La construcción histórica de la profesión médica en Buenos Aires, 1852-1886 (Madrid: Consejo Superior de Investigaciones Científicas, 1999).

20. María Laura Rodríguez y otros, "Prácticas empíricas y medicina académica en Argentina. Aproximaciones para un análisis cuanticualitativo del Primer Censo Nacional (1869)", Historia Crítica 49 (2013): 81-108, doi: 10.7440/histcrit49.2013.05; Adriana Álvarez, "Las distintas asimetrías de enfermar, morir y sanar en el interior de la Provincia de Buenos Aires entre los siglos XIX y XX", Fragmentos de la historia de la salud en la Argentina rural, coords. Adrián Carbonetti y Adriana Álvarez (Villa María: Eduvim, 2013) 13-34.

21. Sobre las denuncias de los médicos véanse los trabajos de Dahhur, "La medicina popular"; Allevi y Carbonetti, "Peticiones y prerrogativas".

22. Pedro Barbieri, El ejercicio de la medicina y el charlatanismo en la República Argentina (Buenos Aires: La Semana Médica, 1905); Alfredo Fernández Verano, El charlatanismo y las enfermedades venéreas (Buenos Aires: La Semana Médica, 1935); Carlos Grau, El charlatanismo en medicina (Buenos Aires: La Semana Médica, 1939). 
a su carta publicada en mayo de 1881, en la cual confluían el llamado a poner fin al curanderismo y la crítica hacia la complicidad de las instancias judiciales. En los “Apuntes de un médico de campaña”, ese mensaje aparece refrendado en más de una oportunidad. En la primera entrega de la serie, Domínguez resume algunas de las dificultades del ejercicio médico en los poblados de la provincia, y entre ellas se cuenta, por ejemplo, el hecho de que, ante la aparición de una enfermedad, los individuos consultarán primero "a las médicas [curanderas] y como último recurso llamarán al médico". ${ }^{23} \mathrm{Al}$ respecto, agrega que los pacientes, "unos por ignorancia, otros por malicia", suelen desobedecer los tratamientos prescritos por el profesional. ${ }^{24}$

Todos esos enunciados reaparecen, en tonos más vivos, en Las confesiones de un médico. En los fragmentos dedicados a narrar sus primeras impresiones en un pueblo de la provincia, el médico español establece el consabido maridaje entre curanderismo e ignorancia; según sus palabras, en esas latitudes había "muchísima ignorancia; muchos, muchísimos pícaros escapados de qué sé yo dónde; y muchísimos, la mara de curanderos y adivinos, y toda una caterva de especuladores que tenían a la campaña como país conquistado". ${ }^{25}$

Desde esta perspectiva, los escritos de Silverio Domínguez implicarían una nueva confirmación, detallada mas no innovadora, de las clásicas descripciones del curanderismo en la campaña bonaerense de la segunda mitad del siglo XIX. Sin embargo, las fuentes analizadas aquí merecen una aproximación alternativa. De hecho, estos documentos ofrecen evidencias relativas a asuntos emparentados, a resultas de lo cual aquella reprobación del curanderismo debe ser, si no impugnada, al menos sí matizada y reinterpretada. La lectura de estas producciones escritas permite establecer que, a los ojos de un agente privilegiado —un médico extranjero que transitó de la medicina de campaña a la vanguardia científica de la capital-, era menester trazar algunas distinciones esenciales, que muy pocas veces fueron tenidas en cuenta por los médicos de aquel periodo. El mensaje transmitido por Domínguez en sus publicaciones puede ser desglosado en tres afirmaciones. Primero, tratándose del universo de las prácticas curativas y la administración de los cuerpos enfermos, la ignorancia era un tópico asaz significativo, pero que no debía ser colocado ni del lado de los curanderos ni de sus clientes habituales. Segundo, bajo ningún punto de vista era tolerable la confusión entre los problemas

23. Silverio Domínguez, “Apuntes de un médico de campaña”, Revista Médico-Quirúrgica (Buenos Aires) 23 de septiembre de 1881:260.Varios testimonios de médicos y viajeros en la provincia de Buenos Aires han insistido en ese punto.Véase, por ejemplo, Henri Armaignac, Viaje por las pampas argentinas. Cacerías en el Quequén Grande y otras andanzas (Buenos Aires: Eudeba, 1976); Juan Fugl, Memorias de Juan Fugl. Vida de un pionero danés durante 30 años en Tandil, Argentina, 18441875 (Buenos Aires: [s.e.], 1989). Véase asimismo Hugo Nario, Tata Dios: el Mesías de la última montonera (Buenos Aires: Plus Ultra, 1976); Juan José Santos, El Tata Dios. Milenarismo y xenofobia en las pampas (Buenos Aires: Editorial Sudamericana, 2008).

24. Domínguez, “Apuntes” 260.

25. Domínguez, Las confesiones 107. 
del curanderismo y de la medicina popular (o lo remedios vulgares). ${ }^{26}$ Tercero, el verdadero flagelo en el arte de curar residía en la intervención de acciones que, de modo liminar, podemos colocar del lado del poder y de la moral. Como una consecuencia de esos tres enunciados, y de su mutua articulación, la conclusión que se desprende es que, a fin de cuentas, el curanderismo era un asunto casi secundario.

La primera sentencia reza, por lo tanto, que, si una ignorancia afectaba las acciones ligadas al cuidado de la salud, debía ser imputada a los médicos. Pocos doctores del Buenos Aires de aquellos años dejaron asentado de modo tan claro que la medicina clínica carecía de remedios eficaces para la mayoría de las enfermedades, sobre todo las más dañinas. ${ }^{27}$ Ya en su escrito acerca de la difteria, Domínguez confesaba: "Cansado y abatido miraba con desconsuelo el triste papel que representamos los médicos, cuando enfrente de una enfermedad mortal y sin armas con que combatirla, nos es forzoso cruzarnos de brazos y meditar sobre la muerte". ${ }^{28}$ En la misma dirección apunta una de las primeras advertencias efectuadas por el autor en su serie sobre la medicina en la campaña. Afirma que un obstáculo para el médico joven que se apresta a auxiliar a los enfermos reside en la incompletitud de los conocimientos adquiridos en la universidad o transmitidos en los libros científicos: "Infinidad de casos nuevos no descritos en las obras didácticas le hacen vacilar sobre la línea de conducta que debe trazarse, y todo confuso y lleno de dudas emplea en muchos casos medicaciones que no responden como debiera esperar al objeto que se propone", ${ }^{29}$

En las páginas de Domínguez se repite una y otra vez ese descontento hacia los límites del saber médico.Y esa suerte de "ignorancia” debe ser aprehendida a la luz de una relocalización del saber llevada a cabo por el autor. En efecto, la proposición acerca del desconocimiento médico aparece contrabalanceada por la presunción de que el conocimiento útil está en otro lado. En todo lo relacionado con el tratamiento de las afecciones, el saber es atribuido a aquello que en su pluma queda referido como lo "popular" o "vulgar". Los escritos tempranos de este médico no son otra cosa que una enfática ponderación de los remedios "caseros" empleados no solamente por los propios enfermos, sino por otros agentes, como, por ejemplo, las comadronas. En todas y cada una de esas intervenciones escritas, Domínguez se dedicó a detallar artefactos curativos "populares" empleados contra diferentes dolencias, sus ingredientes y sus modos de aplicación. Hizo más que eso: brindó testimonio del uso clínico que él efectuó de tales remedios y de la

26. En términos generales, cabe definir a la medicina popular como un cúmulo de conocimientos empíricos adquiridos por las sociedades, transmitidos a través de la tradición oral, que han probado ser eficaces (o que en el imaginario popular lo son). En cambio, el curanderismo es asociado a la práctica ilegal de la medicina por parte de agentes que no tienen una habilitación legal para hacerlo, y que llevan a cabo su accionar a cambio de una remuneración económica.

27. Diego Armus, "Medicina casera, remedios y curanderos en los inicios de la medicalización de la ciudad moderna. Buenos Aires, 1870-1940”, Tempos Históricos 20 (2016): 47-80.

28. Domínguez, Tratamiento 4.

29. Domínguez, “Apuntes" 260. 
efectividad terapéutica que había alcanzado con ellos. Sin importar cuán singular o exótica resultara la composición de esos métodos curativos, el español se empeñó en ensayar su eficacia y modo de acción, y cabe adelantar que en la mayoría de los casos declaró que lograban su cometido y traían, por consiguiente, el alivio que los recursos de la medicina eran incapaces de alcanzar.

La primera entrega de los "Apuntes" resume el ideario que hace las veces de columna vertebral de la serie:

No desdeñe los remedios vulgares, algunos de los cuales sancionados por la experiencia, si bien empleados empíricamente por los aficionados, prestarán en más de una ocasión útiles servicios [...].Yo puedo decir que desde aceptar muchos usos vulgares sancionados por la experiencia, me ha sido más fácil la práctica de la profesión, y nunca me arrepentiré de haber seguido los preceptos a que aludo, pues casi siempre me han dado un resultado satisfactorio. ${ }^{30}$

Tras esa declaración de principios, y convencido de que "nuestra misión es curar las enfermedades, por medios aún los más extraños e incomprensibles", ${ }^{11}$ Domínguez recupera los múltiples remedios caseros que lo habían auxiliado en su tarea clínica. Confiesa haber echado mano de "medio vaso de orinas trasnochadas" para curar una indigestión, de semilla de zapallo criollo triturado en leche para expulsar lombrices intestinales, de tostada empapada en vino colocada sobre el abdomen para sanar la dispepsia, de emplasto de nido de golondrina amasado con vinagre colocado sobre el cuello para la laringitis, etcétera. Esas recetas populares, que "salvan el polvo de los tiempos para llegar hasta nosotros", eran preferibles y más eficaces que "esas mescolanzas de drogas sólidas, líquidas y gaseosas amontonadas unas sobre otras", usadas por los médicos citadinos que se mostraban fieles al "sistema alborotador de removerlo todo con frascos, pociones [y] polvos". 32

Es posible documentar que Domínguez mantuvo en pie esa suerte de proyecto hasta por lo menos el año 1884. En efecto, en un escrito de ese año acerca del empacho, enfatizó: "Siguiendo consecuente con mis ideas, que tienden a investigar la medicina vulgar, porque algo bueno he encontrado en ella". ${ }^{33}$ De todas formas, más que rastrear de modo exhaustivo cómo se hizo presente esa ponderación de los remedios populares en sus escritos de la década de 1880, es interés de este trabajo continuar con el examen de las conclusiones que el autor desplegó a propósito del arte de curar. Ello da pie para analizar el tercero de los tópicos mencionados, que de alguna forma se articula con los dos anteriores. Este asunto puede ser enunciado de la siguiente manera: ni la profusión de curanderos ni el carácter aparentemente no científico de sus procedimientos curativos eran los verdaderos

30. Domínguez, “Apuntes” 260.

31. Domínguez, “Apuntes” 343

32. Domínguez, "Apuntes" 467.

33. Silverio Domínguez, "Empacho", Anales del Círculo Médico Argentino (Buenos Aires) 1 de enero de 1884: 245. 
responsables de las dificultades o los conflictos que obstaculizaban la atención médica en los pueblos de la provincia. Por el contrario, los dos escritos principales de Domínguez brindan sobradas evidencias de que otro tipo de dinámicas y agentes tenían una intervención mucho más significativa y negativa en el ejercicio profesional. El verdadero flagelo resultaba de la confluencia de actores sociales y dinámicas de poder que tenían que ver, por un lado, con la falta de una moral médica, es decir, con la no observancia de preceptos éticos por parte de los diplomados, y, por otro lado, con la facilidad con que agentes sociales ligados al mundo de la política o de la justicia podían decidir la suerte o el destino de médicos y curanderos. ${ }^{34}$ Por último, estaba la cautela que un diplomado debía tener en aras de adecuar sus acciones a los hábitos sociales de la comunidad. Tanto "Apuntes" como la novela de 1882 dan un mensaje muy enfático sobre esos puntos. Es posible incluso establecer que esa última obra ofrece los ejemplos e ilustraciones de enunciados y críticas que el primer escrito despliega desde una perspectiva enteramente doctrinal.

Los capítulos de Las confesiones de un médico dedicados a la vida en la campaña narran una triste sucesión de fracasos e injusticias. Las causas de esos traspiés tienen que ver con lo recién subrayado. El protagonista de esa supuesta ficción debió sobreponerse a los recelos, murmuraciones y a una "chismografia [...] practicada de una manera tan sutil como malévola", suscitada por la llegada de un nuevo habitante, máxime cuando se trataba de un médico. ${ }^{35}$ Esa fría bienvenida iba más allá de los rumores; así, al poco tiempo de llegar al primer poblado, uno de los curanderos encomendó a un "gaucho" que atropellara con su caballo a Felipe/ Silverio, como forma de intimidación. ${ }^{36}$ Esos sanadores, y los vecinos en general, "a cada paso encontraban ocasión para burlárseme, y ponerme en ridículo". ${ }^{37}$ En segundo lugar, la mayor embestida sobrevino cuando los tres curanderos del pueblo le tendieron una suerte de trampa en ocasión de una "interconsulta" sobre una enferma, y se le acusó no solamente de querer envenenar a la paciente, sino de ser un charlatán que carecía de título. Esa acusación fue aprovechada por el juez local para solicitar al Consejo de Higiene la aplicación de una multa por ejercicio ilegal. El magistrado logró su cometido y Felipe/Silverio tuvo que huir del pueblo en aras de esquivar esa reprimenda.

Con el objetivo de no cometer dos veces el mismo error, el protagonista se dirige a un segundo pueblo, y lo primero que hace al llegar es enseñar al juez su título y ganarse su amistad. De todas formas, un tiempo después los enemigos políticos de ese juez se valieron de una intervención del médico para acusarlo a él

34. Ese punto ha sido examinado de modo reciente para el caso de distintas provincias de Argentina por Dahhur, "Las causas"; Dolores Rivero y Laura Vanadía, "En los márgenes de la biomedicina: perspectivas en torno a la práctica ilegal de la medicina en Córdoba y Buenos Aires, 1920-1930", Trashumante. Revista Americana de Historia Social 11 (2018): 98-121, doi: 10.17533/udea.trahs. n11a05; Fleitas.

35. Domínguez, Las confesiones 106.

36. Domínguez, Las confesiones 113.

37. Domínguez, Las confesiones 113. 
y a su protector de haber asesinado a un individuo. Esa inculpación fue ventilada desde los diarios locales y el prestigio del facultativo resultó seriamente herido. ${ }^{38}$ Como resultado, tuvo que mudarse a un tercer pueblo, en el que no tuvo mejor suerte, pues, a pesar de que atendió en varias oportunidades de manera gratuita, fue tildado de "carero" por pacientes a quienes el protagonista trata de "desagradecidos" y "estafadores". ${ }^{39}$ La propagación de esos rumores lo obligó a cambiar nuevamente de pueblo. En su último lugar de residencia cobró protagonismo un obstáculo que aún no había sido tematizado en la novela, pero que sí había retenido la atención del autor en sus "Apuntes": la total ausencia de compañerismo de parte de los médicos, quienes se dejaban guiar por un execrable afán de lucro y no trepidaban en cometer los máximos atropellos contra sus colegas. En Las confesiones ese punto es ilustrado por las fricciones generadas entre los cuatro diplomados que ejercían en ese pueblo, quienes no dudaban en hacer valer sus contactos para quitar los puestos o la clientela a sus compañeros.

Las entregas de los "Apuntes" se encargaron de desarrollar con mayor extensión esos mismos obstáculos, con la explícita intención de acercar consejos prácticos a los médicos que quisieran ejercer su arte en la campaña. De todas maneras, en la publicación aparecida en la Revista Médico-Quirúrgica, el énfasis fue colocado en dos aspectos. Por un lado, en el hecho de que el diplomado debe hacer todo lo posible por acometer un doble movimiento respecto de la vida social que lo rodea: primero, mantenerse por entero al margen de los rumores, las apariencias y las críticas que de alguna forma tiñen todo el entramado social; y segundo, aprender a fondo sus costumbres, sus remedios populares y su cosmovisión general. Por otro lado, también se enfatiza en las funestas consecuencias de la falta de camaradería entre los diplomados; en palabras del autor: "El compañerismo en la campaña es el rara avis de Platón". ${ }^{40}$

\section{Exámenes de reválida y xenofobia profesional}

Las confesiones de un médico contiene información aún más valiosa a propósito de un segundo núcleo temático, referente a la extendida presencia de médicos extranjeros en Argentina durante el último tercio del siglo XIX. Se trata de un asunto acerca del cual la bibliografia histórica es sorprendentemente escasa; luego de la pionera tesis de Alfredo Kohn Loncarica, centrada más en el recuento algo superficial de casos singulares que en un examen del problema global, únicamente Ricardo González Leandri volvió a analizar la temática con herramientas interpretativas bien razonadas. ${ }^{41}$ De todas maneras, sus fuentes y sus conclusiones son exclusivamente válidas para el periodo que se extiende entre 1852 y los

38. Domínguez, Las confesiones 126-127.

39. Domínguez, Las confesiones 141.

40. Domínguez, “Apuntes” 483.

41. González Leandri 35-40. 
inicios de la década de 1870, cuando la llegada de diplomados extranjeros aún no era masiva y no se habían generado los conflictos y recelos que en adelante prevalecerían.

Silverio Domínguez llegó a la ciudad de Buenos Aires en momentos en que la profesión médica atravesaba una de sus conmociones internas más intensas y provechosas, centrada en el cuestionamiento de la vieja élite médica y en la exigencia de renovación de la enseñanza universitaria. ${ }^{42}$ En tal sentido, es entendible que el personaje central de la novela remarcara el clima de "efervescencia y color científico" que primaba en la Facultad. ${ }^{43}$ El orgullo de los médicos locales por la lenta modernización de su casa de estudios fue uno de los motivos por los cuales por esos años los médicos extranjeros comenzaron a constituir un problema digno de atención. En efecto, a partir de la década de 1870 cobró más vigor la sospecha acerca del verdadero valor de los conocimientos de los diplomados llegados de ultramar. Fue así que comenzó a cuestionarse a viva voz si los extranjeros, sobre todo los recibidos en universidades europeas de menor notoriedad, tenían en su haber una formación científica adecuada. Las confesiones de un médico aborda a su manera ese clima de ideas, al poner en boca de su personaje un lamento por la rusticidad de los conocimientos adquiridos en España: "Así es que conocí mi pequeñez, y deploré amargamente no haber hecho mi carrera de una manera más fructífera". ${ }^{44}$

Ahora bien, el motivo que mayor peso tuvo en la franca modificación que se produjo en la representación del médico extranjero en esos años, se halla en las cifras. Para empezar con un número más bien general, es preciso recordar que, según el recuento global realizado por Kohn Loncarica, entre 1871 y 1915 se recibieron en la Facultad de Medicina de Buenos Aires 2,024 profesionales, y durante ese mismo lapso unos 700 doctores extranjeros revalidaron sus diplomas en la misma casa de estudios. ${ }^{45}$ Lo anterior significa que, por esos años, una cuarta parte de los médicos habilitados para ejercer su arte en el país había obtenido su título en universidades del extranjero. ${ }^{46}$ Sin embargo, esa cifra debe ser matizada en un doble sentido. Primero, es obvio que la cantidad de médicos extranjeros que ejercieron su arte fue mucho mayor, pues muchos de ellos jamás rindieron la reválida y trabajaron largos años en pueblos del interior que carecían de diplomados. Segundo, tal y como ha

42. Pablo Souza, "Una 'república de las Ciencias Médicas’ para el desierto argentino. El Círculo Médico Argentino y la inscripción de un programa experimental en las ciencias médicas de Buenos Aires (1875-1914)" (Tesis de doctorado en Historia, Universidad de Buenos Aires, 2014).

43. Domínguez, Las confesiones 97.

44. Domínguez, Las confesiones 101.

45. Kohn Loncarica 14-15.

46. Esa proporción podía ser mayor en grandes conglomerados urbanos, elegidos con preferencia por los médicos foráneos. Por ejemplo, de acuerdo con el relevamiento municipal hecho en septiembre de 1887, el 36 por ciento de los médicos que habitaban el territorio de la ciudad capital era de procedencia extranjera (159 del total de 436). Censo General de población, edificación, comercio e industrias de la Ciudad de Buenos Aires capital federal de la República Argentina. Levantado en los días 17 de agosto, 15 y 30 de septiembre de 1887, t. II (Buenos Aires: Compañía Sud-Americana de Billetes de Banco, 1889) 43. 
sido documentado de modo reciente, los consejos de higiene provinciales podían otorgar reválidas sin el concurso de la universidad, y por ese motivo esos médicos "habilitados" no son contemplados por el cálculo de Kohn Loncarica. ${ }^{47}$

La novela de Domínguez contiene dos escenas muy valiosas, sobre todo por su valor testimonial, en lo relacionado con el lugar de los médicos extranjeros a fin de siglo. La primera de ellas se refiere a la actitud con que el protagonista enfrenta la noticia sobre la obligatoriedad del examen de reválida. Dado que en España le habían advertido que en Buenos Aires no era necesaria una homologación de su diploma, el médico exterioriza su sorpresa al saber que "Aquí el diploma es un papel mojado que para nada sirve" si su dueño no se somete a la reválida. ${ }^{48}$ En palabras de Felipe, la Facultad "exige pruebas formales y decisivas, competencia demostrada en los dos exámenes, teórico el uno y eminentemente práctico el otro". ${ }^{49}$ Por extraño que ello resulte, esas páginas de la novela constituyen uno de los escasos testimonios que echan cierta luz sobre el procedimiento formal de la reválida y las dificultades que podía significar para algunos de los postulantes. Hasta ahora se conocían solo dos fuentes que incluyesen algunos detalles acerca de esa misma problemática: el primer y único número de la Guía Médica de Buenos Aires de Florencio Fernández Gómez y algunos pasajes del Código Médico Argentino de Emilio Coni. Ahora bien, estos últimos documentos no ofrecían otra cosa que la transcripción de los formularios con que se solicitaba fecha para ese examen y la reproducción de los artículos reglamentarios referidos a esa prueba. Las confesiones acerca, por fin, un cuadro más completo sobre esa instancia que tanta significación tuvo para el destino profesional de los diplomados foráneos.

Según Domínguez — que, sin lugar a dudas, en estas páginas no hace otra cosa que recordar su experiencia de reválida de 1878 - la prueba teórica duraba una hora y media, y en ella se ponía mucho énfasis en la cirugía operatoria y la oftalmología. ${ }^{50}$ Las asignaturas a evaluar en esa prueba teórica eran: anatomía descriptiva, topográfica y patológica; histología; fisiología; patología general; materia médica; terapéutica; higiene; historia de la medicina; medicina legal, y toxicología. En el examen práctico se exigían "dos operaciones hechas delante del tribunal; dos historias clínicas, una de medicina y otra de cirugía a la cabecera del enfermo, y un caso de oftalmología de la misma manera". ${ }^{51}$ Además, el autor señala que, para rendir el examen, el candidato debía abonar previamente cinco mil pesos. No solo los

47. Allevi y Carbonetti, "Peticiones y prerrogativas".

48. Domínguez, Las confesiones 97-98.

49. Domínguez, Las confesiones 98.

50. Domínguez, Las confesiones 98 . En efecto, esas dos especialidades tuvieron un lugar esencial en la renovación de la disciplina médica porteña en la década de 1870, y ambas fueron ampliamente difundidas desde las páginas de la Revista Médico-Quirúrgica (en cuyas páginas ocuparon una función destacada los dos principales especialistas en esas áreas: Ignacio Pirovano y Pedro Roberts. Oscar Andrés Vaccarezza, Ignacio Pirovano, cirujano del 80 (Buenos Aires: Ediciones Culturales Argentinas, 1981).

51. Domínguez, Las confesiones 98. 
médicos extranjeros lamentaron la existencia de esas matrículas y emolumentos, sino que esa "mercantilización del saber" generó fuertes debates entre estudiantes y profesores de la Facultad de Medicina. ${ }^{52}$

Cuando Domínguez llegó al país, el descontento hacia los médicos extranjeros estaba referido sobre todo a su resistencia a rendir la reválida. Como ya ha sido señalado, para algunos de esos diplomados, el idioma, el costo o incluso el contenido de la prueba podían aparecer como elementos disuasivos, ${ }^{53}$ máxime cuando la ley los autorizaba a evitar la reválida siempre y cuando aceptaran trabajar en pueblos apartados. Ahora bien, en las últimas dos décadas del siglo, cuando el volumen de las oleadas inmigratorias creció de modo sustancial, aquel descontento fue reemplazado poco a poco por una objeción distinta. Tanto desde la prensa general como desde la literatura médica se criticó en duros términos el examen mismo; fue tildado de superficial y se citaba con alarma la gran cantidad de médicos extranjeros que pasaban exitosamente la prueba. Ese pavor podía tener sustento, pues durante algunos de esos años la cantidad de médicos que revalidaban su diploma podía resultar igual o incluso superior a la cifra de egresados de la universidad local. ${ }^{54}$ Distintas voces comenzaron a hacer referencia a "un examen breve y lleno de consideraciones por parte de los profesores". ${ }^{55}$ De acuerdo con una columna de septiembre de 1891, esas pruebas "no presentan mayor dificultad para los que habiendo dragoneado en Europa sólo de practicantes o ayudantes de anfiteatro obtengan aquí título de suficiencia médica". ${ }^{56}$ Por esas mismas fechas, médicos de gran prestigio local comenzaron a exigir la modificación del reglamento universitario; la petición era que el examen único de reválida fuera reemplazado por otro sistema, en el cual el candidato tuviera que rendir un examen por cada una de las asignaturas de la carrera, como si se tratase de un alumno libre. ${ }^{57}$ La campaña surtió efecto, y en septiembre de 1893, la Facultad de Medicina efectuó el cambio anhelado. ${ }^{58}$

Antes incluso de que el método de la reválida figurara en el centro de las polémicas, otra acusación contra los médicos extranjeros circuló en diarios y revistas

52. Souza 65-68.

53. González Leandri.

54. Eso sucedió, por ejemplo, en 1890 y 1892. Para establecer esas comparaciones véase "Facultad de Ciencias Médicas", Anales del Departamento Nacional de Higiene (Buenos Aires) 1 de septiembre de 1893: 301-304.

55. "Los médicos extranjeros", Sud-América (Buenos Aires) 23 de marzo de 1891: 2.

56. "Los médicos extranjeros", Sud-América (Buenos Aires) 8 de septiembre de 1891: 3.

57. Ese pedido fue realizado, entre otros, por Samuel Gache. Véase Samuel Gache, "Exámenes de médicos extranjeros", Anales del Círculo Médico Argentino (Buenos Aires) 1 de septiembre de 1891: 559-560; José María Ramos Mejía, "Revalidación de diplomas de médicos extranjeros", Anales de Higiene Pública y Medicina Legal (Buenos Aires) 1 de junio de 1892: 207-208.

58. Archivo de la Facultad de Medicina de la Universidad de Buenos Aires (AHFMUBA), Buenos Aires, r-087, d1-01-30, f. 9. La ordenanza se reproduce en Guía Médica Argentina (Buenos Aires) 1 de enero de 1899: 136-137. 
de la ciudad de Buenos Aires: la sospecha de que los presuntos diplomados poseían títulos falsificados. En ese sentido, la novela de 1882 se transforma una vez más en una fuente asaz esclarecedora. Según la narración, cuando el protagonista era "más capaz para sufrir el examen después de haber hecho un concienzudo estudio", 59 se dirigió a Buenos Aires para tramitar su reválida. De acuerdo con sus cálculos, la prueba debía tener lugar apenas unos días más tarde, pero desde la Secretaría de la Facultad le informaron que debía esperar al menos un mes más y no le dieron explicación de esa extraña demora. Para colmo de males, cada vez que se acercaba a consultar por su pedido, el secretario lo miraba de modo extraño y evitaba hablar con él; durante cuatro meses, tanto el decano como el secretario siguieron mostrando hacia él la misma displicencia. Harto de ese trato, el médico acudió a la oficina dispuesto a armar un escándalo, pero "fui desarmado por la benévola acogida del secretario, el que de manos a boca me dijo que al día siguiente podía examinarme". ${ }^{60}$ Luego de que el funcionario le pidiera sinceras disculpas por la tardanza, el candidato recibió la explicación de lo ocurrido: "La facultad de medicina recibió una nota en que prevenían que yo no era médico, y solo un aficionado, y que si presentaba diploma, con toda seguridad era falsificado, creyendo hacer un bien a la facultad con prevenirla para que no fuese sorprendida incautamente". ${ }^{61}$ Ante esa acusación, la Facultad había procedido a hacer averiguaciones en España para comprobar la autenticidad del diploma. Una vez que todo fue resuelto, el médico pasó con éxito la reválida.

Al respecto, cabe realizar dos señalamientos, y ambos apuntan a reforzar la verosimilitud de ese fragmento aparentemente ficcional. ${ }^{62}$ En primera instancia, es menester tomar en consideración cuán presente estaba la sospecha sobre falsificación de diplomas en los ámbitos profesionales de esos años. Por ejemplo, si se dirige la mirada a la principal revista del gremio médico, es posible comprobar que en esas fechas se multiplicaron los rumores y la preocupación a propósito de ese delito, lo cual se manifestó de varias maneras. En algunas oportunidades, se alertó directamente sobre la publicación en los diarios generales de avisos de presuntos vendedores de diplomas médicos; así, en junio de 1880, la Revista Médico-Quirúrgica reprodujo un aviso aparecido en La Prensa unos días antes, donde un tal "Medicus" ofrecía ese servicio fraudulento. ${ }^{63}$ Posteriormente, casi de modo simultáneo, tuvo lugar un eco a nivel local de las acciones de John Buchanan, el famoso falsificador de diplomas que en la década de 1870 llevó adelante su negocio en Estados Unidos, quien fue llevado a la justicia en múltiples oportunidades ${ }^{64} \mathrm{El}$ órgano de

59. Domínguez, Las confesiones 130.

60. Domínguez, Las confesiones 133.

61. Domínguez, Las confesiones 133.

62. Por desgracia, no se conserva el expediente académico de Silverio Domínguez en el AHFMUBA.

63. "Venta de diplomas", Revista Médico-Quirúrgica (Buenos Aires) 8 de junio de 1880: 99.

64. David Alan Johnson, Diploma Mill: The Rise and Fall of Dr. John Buchanan and the Eclectic Medical College of Pennsylvania (Kent:The Kent State University Press, 2018). 
prensa de los médicos porteños se ocupó de divulgar noticias sobre las acciones judiciales emprendidas contra aquel criminal, a quien se acusaba de haber vendido unos 60 mil diplomas a compradores de Europa y América. ${ }^{65}$ Hubo, finalmente, un tercer modo a través del cual los médicos de Buenos Aires manifestaron su inquietud por la supuesta circulación de diplomas falsos: las airadas acusaciones que se lanzaron desde la capital por presuntas irregularidades ocurridas en la Universidad de Córdoba. Tanto los médicos como los farmacéuticos de Buenos Aires llevaron adelante una campaña de desprestigio de la casa de estudios cordobesa y, entre otras cosas, se señaló que allí se concedían, a cambio de dinero, certificados de aprobación de materias e incluso diplomas profesionales. ${ }^{66}$

En segunda instancia, se encontró un punto que quizá sea más significativo: es posible aseverar que el percance sufrido por el protagonista de la novela no pertenece exclusivamente al terreno ficcional. Si bien la documentación disponible no permite determinar el carácter autobiográfico de ese incidente, sí es posible reconstruir que otros médicos extranjeros pasaron por episodios muy similares ante las autoridades de la Facultad de Medicina ${ }^{67}$ Existe constancia de que en al menos una oportunidad un diplomado foráneo fue víctima del mismo mecanismo de denuncia anónima (de falsificación de diploma), que fue tomado muy en serio por los funcionarios, quienes dispusieron los mismos procedimientos de averiguación relatados por Domínguez. Se trata de lo ocurrido con el médico de origen rumano Hugo Marcus, quien arribó a Buenos Aires en 1889 y, un año más tarde, en agosto de 1890, revalidó su diploma (obtenido en París) ante la Facultad local. ${ }^{68}$ Unos meses después, Marcus se vio envuelto en un resonado escándalo, ya que se le acusó de aplicar con sus pacientes muestras falsificadas de un remedio. Entre los artículos aparecidos en la prensa en su contra, figuró un extenso escrito del cónsul del Imperio austrohúngaro, en el cual se reproducían varios documentos que la embajada había reunido para demostrar que el individuo rumano en verdad no poseía un título médico. ${ }^{69}$ Tras una acusación tan seria, el Departamento Nacional de Higiene pidió a la Facultad que hiciera las averiguaciones necesarias para determinar la legitimidad del título médico de Marcus. ${ }^{70}$ Mientras eso sucedía, un diario alemán publicó un largo texto anónimo - aunque la redacción aclaraba que su autor era un profesor de la universidad-, en el cual se hacían las

65. "Falsos diplomas", Revista Médico-Quirúrgica (Buenos Aires) 8 de agosto de 1880: 192; “60.000 diplomas falsos", Revista Médico-Quirúrgica (Buenos Aires) 23 de agosto de 1881:215.

66. "Facultad de Medicina de Córdoba", Revista Médico-Quirúrgica (Buenos Aires) 8 de agosto de 1882: 154 .

67. Otros estudiosos han mostrado que la denuncia de títulos falsos fue ampliamente usada contra los médicos extranjeros en otros países de la región. Patricia Palma y José Ragas, "Desenmascarando a los impostores: los médicos profesionales y su lucha contra los falsos médicos en Perú", Salud Colectiva 15 (2019): 1-14, doi: 10.18294/sc.2019.2162.

68. "Hugo Marcus", Buenos Aires, 1890. AHFMUBA, Buenos Aires, leg. 9126, f. 2.

69. "Zur Affaire Hugo Marcus", Deutsche La Plata Zeitung (Buenos Aires) 14 de enero de 1891: 2.

70. "Departamento Nacional de Higiene”, Sud-América (Buenos Aires) 21 de enero de 1891: 2. 
peores imputaciones sobre Marcus: si bien era cierto que comenzó sus estudios en París, había sido expulsado de la universidad debido a faltas graves. Tras ello, se había hecho de su diploma mediante un ardid algo novelesco: según el autor de la nota anónima, algunos años antes, un tal doctor Munro publicó avisos en diarios alemanes en los que ofrecía puestos en América del Norte para egresados de Medicina. Los interesados debían remitirle por correo sus diplomas. Era, a todas luces, una estafa. Pues bien, un doctor alemán cayó en la trampa, envió su título, y luego averiguó que las cartas destinadas a Munro eran recibidas por un tal Hugo Marcus, quien poco después viajó a Buenos Aires. ${ }^{71}$ Lo valioso de todo ese episodio no reside solamente en comprobar hasta qué punto las sospechas de falsificación de diplomas podían dar lugar a acusaciones que eran tramitadas por vías formales, sino también en el hecho de que aquella nota del 5 de febrero fue incorporada al legajo académico de Marcus, cuya traducción al castellano fue solventada por la propia Facultad, según consta en ese mismo expediente. ${ }^{72}$ En síntesis, es evidente que, al igual que en la escena recuperada en la novela de Domínguez, esa acusación anónima de falsificación fue tomada a pie juntillas por los funcionarios universitarios. $^{73}$

\section{A modo de conclusión}

En estas páginas se ha intentado recuperar escritos tempranos de Silverio Domínguez, con la convicción de que conforman un testimonio invalorable acerca de procesos y dinámicas que afectaron sustancialmente la cultura sanitaria bonaerense del último cuarto del siglo XIX. Se ha puesto el énfasis, por un lado, en el modo en que esas fuentes colaboran a una mejor comprensión del ejercicio de las prácticas de curar en esas latitudes, ya que los textos de aquel médico español ayudan a comprender con mejor luz los conflictos efectivos que debían atravesar los agentes sanitarios de ese contexto, los cuales estaban más relacionados con la necesidad de amoldar su accionar a la cultura popular (o a no despertar el enojo de las autoridades políticas o judiciales), que con la competencia con curanderos y sanadores. Por otro lado, la lectura de estas fuentes ilustra algunas de las dificultades que sufrieron los cuantiosos médicos extranjeros que decidieron probar suerte en la región.

Asimismo, cabe atender la posible objeción sobre el carácter excepcional de los puntos de vista defendidos por Domínguez (verbigracia, a propósito de la medicina popular) o de su particular itinerario profesional. Sin la pretensión de disolver por completo la naturaleza inusual o asombrosa del camino recorrido por aquel facultativo, desde médico casi rural hasta pionero de la bacteriología más avanzada, se considera que el mismo refleja una transición que afectó a gran

71. "Hugo Marcus”, Argentinisches Tageblatt (Buenos Aires) 5 de febrero de 1891: 1.

72. "Hugo Marcus”, Buenos Aires, 1890. AHFMUBA, Buenos Aires, leg. 9126, f. 9.

73. Finalmente se comprobó la autenticidad del título médico de Marcus.Véase "El Dr. Hugo Marcus", La Nación (Buenos Aires) 3 de octubre de 1891: 2. 
parte de sus colegas. De este modo, los pasos seguidos por Domínguez vuelven a tener valor paradigmático. En efecto, luego de su fascinación con los remedios populares (sustentada en un consciente descontento con el saber médico oficial) y de forma simultánea a su instalación en la ciudad de Buenos Aires, se observa que el diplomado dirigió en otra dirección su pedido de auxilio. Si hasta entonces había buscado en la tradición popular un saber eficaz, en los primeros años de la década de 1880 canalizó esa demanda hacia el universo de la técnica que lentamente comenzaba a influenciar el ejercicio de la medicina. Fueron los años en que exteriorizó su admiración por la electroterapia, la metaloterapia, la hidroterapia o los aparatos de zinc para la reducción de fracturas. ${ }^{74}$ Se trató, por así decirlo, de un periodo de transición en el que se mostró atento y expectante hacia toda novedad terapéutica que prometiera vigorizar la alicaída eficacia de la medicina. Tras esa etapa, sobrevino su conversión al credo pasteuriano, del que fue un convencido difusor en la ciudad de Buenos Aires. Así, se considera que, tanto su adhesión a los remedios populares, como su posterior optimismo acerca de los aportes de la técnica, resumen en verdad la progresión de una parte importante del gremio médico, que por esos mismos años (la década de 1880) cifró el futuro de la medicina en su permeabilidad para con otras ciencias pujantes (piénsese, en tal sentido, en el valor de la química para la lenta instalación de la antisepsia, y luego la asepsia en cirugía, que permitió revolucionar la eficacia quirúrgica de los doctores).

El caso de Domínguez es, por lo tanto, una demostración de una ventana temporal en la que nuevas prácticas y nuevas formas de entender la medicina comenzaban a circular y a gestarse dentro de la corporación médica. Su testimonio permite a los historiadores matizar cuestiones ligadas al estado sanitario de la provincia de Buenos Aires, el cual aún continúa generando más de una incógnita.

\section{Fuentes}

\section{Manuscritas}

Archivo Histórico de la Facultad de Medicina de la Universidad de Buenos Aires, Buenos Aires (AHFMUBA)

\section{Impresas}

Armaignac, Henri. Viaje por las pampas argentinas. Cacerías en el Quequén Grande y otras andanzas. Buenos Aires: Eudeba, 1976.

Barbieri, Pedro. El ejercicio de la medicina y el charlatanismo en la República Argentina.

74. Silverio Domínguez, Tratamiento; “El baño turco romano”, La Prensa (Buenos Aires) 10 de mayo de 1884: 4; "Metaloterapia. Artritis reumáticas curadas por las cadenas metálicas", Anales del Círculo Médico Argentino (Buenos Aires) 1 de marzo de 1884: 358-361; “Aparatos de zinc laminado para el tratamiento de las fracturas”, Anales del Círculo Médico Argentino (Buenos Aires) 1 de enero de 1885: 29-33. 
Buenos Aires: La Semana Médica, 1905.

Censo General de población, edificación, comercio e industrias de la Ciudad de Buenos Aires capital federal de la República Argentina. Levantado en los días 17 de agosto, 15 y 30 de septiembre de 1887. Tomo II. Buenos Aires: Compañía SudAmericana de Billetes de Banco, 1889.

Coni, Emilio R. Código Médico Argentino. Recopilación y resumen de la legislación y jurisprudencia sobre la profesión, deberes y derechos de los médicos, farmacéuticos y parteras. Buenos Aires: Imprenta de Pablo E. Coni, 1879.

Domínguez, Silverio. La tuberculosis o confidencias microbianas. Buenos Aires: Imprenta Roma, 1894.

. Las confesiones de un médico. Buenos Aires: Imprenta de El Correo Español, 1882.

. Perfiles de una llaga social. Buenos Aires: Imprenta de Pablo Coni, 1881.

. Tratamiento de la difteria. Buenos Aires: Imprenta de Pablo Coni, 1880.

Fernández Gómez, Florencio. Guía médica de Buenos Aires. Buenos Aires: Imprenta Europea, 1893.

FernándezVerano, Alfredo. El charlatanismo y las enfermedades venéreas. Buenos Aires: La Semana Médica, 1935.

Grau, Carlos. El charlatanismo en medicina. Buenos Aires: La Semana Médica, 1939.

\section{Periódicos y revistas}

Anales del Círculo Médico Argentino (Buenos Aires) 1884, 1885, 1891, 1892.

Anales del Departamento Nacional de Higiene (Buenos Aires) 1893.

Anales de Higiene Pública y Medicina Legal (Buenos Aires) 1892.

Anuario Bibliográfico de la República Argentina (Buenos Aires) 1883.

Argentinisches Tageblatt (Buenos Aires) 1891.

Deutsche La Plata Zeitung (Buenos Aires) 1891.

Guía Médica Argentina (Buenos Aires) 1899.

La Nación (Buenos Aires) 1891.

La Prensa (Buenos Aires) 1884.

Revista Médico-Quirúrgica (Buenos Aires) 1880-1882.

Sud-América (Buenos Aires) 1891.

\section{Bibliografía}

Allevi, José Ignacio, Adrián Carbonetti y Paula Sedrán. “Médicos, administradores y curanderos. Tensiones y conflictos al interior del arte de curar diplomado en la Provincia de Santa Fe, Argentina (1861-1902)". Anuario de Estudios Americanos 75.1 (2018): 295-322. Doi: 10.3989/aeamer.2018.1.11.

Allevi, José Ignacio y Adrián Carbonetti. "Peticiones y prerrogativas. Médicos y boticarios en la corporativización del arte de curar y la conformación del Estado provincial en Santa Fe, Argentina (1857-1903)". Varia Historia 
35.69 (2019): 753-786. Doi: 10.1590/0104-87752019000300004.

Álvarez, Adriana. "Las distintas asimetrías de enfermar, morir y sanar en el interior de la Provincia de Buenos Aires entre los siglos XIX y XX". Fragmentos de la historia de la salud en la Argentina rural. Coords. Adrián Carbonetti y Adriana Álvarez.Villa María: Eduvim, 2013.

Armus, Diego. "Medicina casera, remedios y curanderos en los inicios de la medicalización de la ciudad moderna. Buenos Aires, 1870-1940”. Tempos Históricos 20 (2016): 47-80.

Dahhur, Astrid. "La medicina popular a través de las fuentes judiciales. El proceso de medicalización en la provincia de Buenos Aires a fines del siglo XIX y mediados del siglo XX”.e-l@tina. Revista Electrónica de Estudios Latinoamericanos 17.66 (2019): 48-67.

. "Las causas del curanderismo según la prensa en Tandil y en Buenos Aires a principios del siglo XX”. Question 1.59 (2018): 1-19. Doi: 10.24215/16696581e063.

Di Liscia, María Silvia. Saberes, terapias y prácticas médicas en Argentina (1750-1910). Madrid: Consejo Superior de Investigaciones Científicas, 2002.

Fleitas, Mirta. "¡Queremos a Mano Santa!: actores y significados de una revuelta popular acontecida en 1929 en San Salvador de Jujuy”. Salud Colectiva 3.3 (2007): 301-313. Doi: 10.18294/sc.2007.149

Fugl, Juan. Memorias de Juan Fugl. Vida de un pionero danés durante 30 años en Tandil, Argentina, 1844-1875. Buenos Aires: [s.e.], 1989.

González Leandri, Ricardo. Curar, persuadir, gobernar. La construcción histórica de la profesión médica en Buenos Aires, 1852-1886. Madrid: Consejo Superior de Investigaciones Científicas, 1999.

Johnson, David Alan. Diploma Mill: The Rise and Fall of Dr. John Buchanan and the Eclectic Medical College of Pennsylvania. Kent: The Kent State University Press, 2018.

Kohn Loncarica, Alfredo. "Historia de la inmigración médica en la República Argentina". Tesis de doctorado en Medicina, Universidad de Buenos Aires, 1981.

Nario, Hugo. Tata Dios: el Mesías de la última montonera. Buenos Aires: Plus Ultra, 1976.

Palma, Patricia y José Ragas. "Desenmascarando a los impostores: los médicos profesionales y su lucha contra los falsos médicos en Perú”. Salud Colectiva 15 (2019): 1-14. Doi: 10.18294/sc.2019.2162.

Podgorny, Irina. Charlatanería y cultura científica en el siglo XIX. Madrid: Libros de la Catarata, 2015.

Rivero, Dolores y Laura Vanadía. “En los márgenes de la biomedicina: perspectivas en torno a la práctica ilegal de la medicina en Córdoba y Buenos Aires, 1920-1930". Trashumante. Revista Americana de Historia Social 11 (2018): 98-121. Doi: 10.17533/udea.trahs.n11a05.

Rodríguez, María Laura y otros. “Ocupaciones de la salud en el territorio argentino: 
perspectivas a partir de los censos nacionales de 1869, 1895 y 1914". Política \& Sociedad 25.1 (2018): 75-101.

Rodríguez, María Laura y otros. "Prácticas empíricas y medicina académica en Argentina. Aproximaciones para un análisis cuanticualitativo del Primer Censo Nacional (1869)". Historia Crítica 49 (2013): 81-108. Doi: 10.7440/histcrit49.2013.05.

Rojas, Nicolás. "Conocimientos bacteriológicos, trayectorias institucionales e intervención sanitaria: la creación del Instituto Bacteriológico del Departamento Nacional de Higiene (1886-1904)". Tesis de licenciatura en Historia, Universidad Nacional de Quilmes, 2019.

Romero de Torres, Eva. El Gaucho de Dios. Vida y obra de Pancho Sierra. Merlo: El Triángulo, 1982.

Santos, Juan José. El Tata Dios. Milenarismo y xenofobia en las pampas. Buenos Aires: Editorial Sudamericana, 2008.

Sanz Hernández, Alexia. "El método biográfico en investigación social: potencialidades y limitaciones de las fuentes orales y los documentos personales". Asclepio 57.1 (2005): 99-115. Doi: 10.3989/asclepio.2005.v57.i1.32.

Souza, Pablo. “Una 'república de las Ciencias Médicas' para el desierto argentino. El Círculo Médico Argentino y la inscripción de un programa experimental en las ciencias médicas de Buenos Aires (1875-1914)". Tesis de doctorado en Historia, Universidad de Buenos Aires, 2014.

Vaccarezza, Oscar Andrés. Ignacio Pirovano, cirujano del 80. Buenos Aires: Ediciones Culturales Argentinas, 1981. 